\title{
OPTIMALISASI DAN ANALISIS DESAIN PARAMETER SEISMIK 3D DARAT BERDASARKAN MODEL GEOLOGI LAPANGAN "RL"
}

\author{
Ravide Lubis, Bagus S. Mulyatno, Karyanto \\ Jurusan Teknik Geofisika, Universitas Lampung \\ J1. Prof. Sumantri Bojonegoro No.1 Bandar Lampung 35145 \\ Email : ravide.loebis@gmail.com
}

\begin{abstract}
ABSTRAK
Desain parameter seismik 3D darat merupakan tahapan awal sebelum akuisisi data seismik 3D darat untuk memperoleh kualitas data seismik dan anggaran survei yang efisien. Tujuan penelitian desain parameter seismik 3D darat ini untuk memperoleh kualiatas data seismik 3D darat yang tinggi berdasarkan penyebaran fold coverage pada masing-masing lapisan target. Adapun metode yang digunakan yaitu berdasarkan prinsip penjalaran gelombang (ray tracing) pada masing-masing lapisan target dimana di setiap titik pantul gelombang (bin) akan memiliki nilai fold yang berbeda sehingga dibutuhkan pemilihan konfigurasi bentangan yang akan menghasilkan penyebaran fold yang optimal. Konfigurasi bentangan yang diterapkan, yaitu orthogonal, brick, zig-zag dan slanted, dimana masing-masing konfigurasi bentangan menggunakan dua tipe template yaitu narrow dan wide azimuth. Dari hasil analisis simulasi rekaman beberapa konfigurasi bentangan di area survei, maka diperoleh konfigurasi bentangan optimal yang akan diterapkan di area survei. Konfigurasi bentangan yang diterapkan, yaitu konfigurasi bentangan orthogonal dengan tipe template narrow azimuth. Pertimbangan pemilihan konfigurasi bentangan ini karena memiliki penyebaran fold yang lebih merata pada lapisan target dibandingkan dengan konfigurasi bentangan yang lain. Selanjutnya untuk memperoleh konfigurasi bentangan yang sesuai kondisi lapangan, maka dilakukan pemindahan titik source di luar zona obstacle (halangan), supaya kualitas data seismik tetap terjaga.
\end{abstract}

\begin{abstract}
The design of 3D land seismic parameters is a preliminary step before the acquisition of 3D land seismic data to obtain seismic data quality and efficient survey budget. The objective of this research is to obtain high quality of 3D land seismic data based on fold coverage spread on each target layer. The method used is based on the principle of wave propagation or ray tracing method on each target layer, wherein each wave reflection point (bin) will have a different value of fold so that the required configuration of the stretch that will result in the optimal spread of the fold. The applied stretch configurations are orthogonal, brick, zig-zag and slanted where each stretch configuration uses two types of templates that is narrow and wide azimuth. From the simulation analysis results of several stretch configurations in the survey area, then the optimal stretch configuration will be obtained in the survey area. The stretch configuration will be applied is the configuration of orthogonal stretch with narrow azimuth type template. Consideration of the selection of this stretch configuration because it has a more evenly folding effect on the target layer than with other stretch configurations. Furthermore, to obtain the configuration of the appropriate stretch of field conditions, the source point is moved outside the obstacle zone so that the quality of seismic data is maintained.
\end{abstract}

Keywords - Design of 3D land seismic parameter, Stretch configurations, Quality of seismic data. 


\section{PENDAHULUAN}

\subsection{Latar Belakang}

Sebelum pelaksanaan akuisisi data seismik, maka tahapan awal yang perlu dilakukan, yaitu penentuan desain survei seismik. Desain survei seismik merupakan tahapan dalam pemilihan parameter akuisisi data seismik dengan mempertimbangkan target yang akan dicapai dan masalah-masalah yang akan timbul saat proses akuisisi data. Parameter akuisisi seismik dari suatu lapangan biasanya tidak sama dengan lapangan yang lain. Penentuan parameter akuisisi seismik bertujuan untuk menetapkan parameter awal dalam suatu rancangan survei seismik yang dipilih sedemikian rupa, sehingga dalam pelaksanaannya akan memperoleh informasi target selengkap mungkin dan noise serendah mungkin ( $\mathrm{S} / \mathrm{N}$ ratio tinggi). Secara tidak langsung, parameter akuisisi yang diterapkan akan sangat berpengaruh terhadap kualitas data seismik yang diperoleh (Chouch dan Mari, 2006).

Belakangan ini, perancangan desain survei seismik sudah mulai menerapkan ray tracing modelling (pemodelan penjalaran gelombang) untuk memetakan titik pantul gelombang yang terbentuk pada sutu reflektor, sehingga dengan demikian para perancang desain survei seismik dapat memprediksi kualitas data seismik dengan lebih detail. Secara prinsipnya, metode pemodelan penjalaran gelombang ini menerapkan teori penjalaran gelombang pada suatu medium terhadap suatu model geologi bawah permukaan yang telah diketahui parameter fisisnya. Secara spesifik, metode penjalaran gelombang dapat diterapkan untuk menentukan analisis illumination atau analisis sebaran full fold migration pada suatu lapisan target dari survei seismik (Fuchsluger, 2011).

\subsection{Tujuan Penelitian}

Adapun tujuan penelitian sebagai berikut:

1. Menentukan parameter desain survei seismik 3D yang optimal berdasarkan parameter target Lapangan RL.
2. Optimalisasi pemilihan konfigurasi bentangan dan tipe template dalam rangka mendapatkan kualitas data seismik yang memiliki $S / N$ ratio yang tinggi.

3. Menganalisis kualitas data seismik 3D berdasarkan hasil simulasi rekaman desain parameter seismik 3D di Lapangan RL.

4. Membuat desain survei seismik 3D darat yang telah sesuai dengan kondisi geologi dan lingkungan di Lapangan RL.

\section{TINJAUAN PUSTAKA}

\subsection{Petroleum System}

Petroleum System merupakan sebuah sistem yang menjadi panduan utama dalam eksplorasi hidrokarbon. Sistem ini digunakan untuk mengetahui keadaan geologi, dimana minyak dan gas bumi terakumulasi (Koesoemadinata,1980). Secara umum sistem terbentuknya minyak dan gas bumi atau disebut juga petroleum system yang terdiri atas: batuan sumber, batuan reservoar, batuan penyekat, perangkap dan migrasi.

\section{TEORI DASAR}

\subsection{Gelombang Seismik}

Gelombang secara umum adalah fenomena perambatan gangguan dalam medium disekitarnya. Gelombang seismik adalah jenis gelombang dengan media penjalarannya bumi. Gelombang seismik disebut juga gelombang elastik karena osilasi partike-partikel medium terjadi akibat interaksi antara gaya gangguan (gradient stress) melawan gaya-gaya elastik. Dari interaksi ini dapat muncul gelombang longitudinal (gelombang akustik), gelombang transversal atau kombinasi keduanya (Sherif dan Geldart 1995)

Menurut cara bergetarnya, gelombang seimik terbagi atas dua tipe gelombang, yaitu Gelombang $P$ dan Gelombang $S$. Menurut Lowrie, 2007 bahwa Gelombang 
$P$ melewati suatu medium secara dilatasi dan kompresi. Persamaan gelombang kompresi dalam arah $\mathrm{x}$,

$\frac{\partial^{2} \theta}{\partial t^{2}}=\alpha^{2} \frac{\partial^{2} \theta}{\partial x^{2}}$

Dimana $\alpha$ adalah kecepatan gelombang $\mathrm{P}$ yang dirumuskan sebagai berikut,

$\alpha=\sqrt{\frac{\lambda+2 \mu}{\rho}}=\sqrt{\frac{K+\frac{4}{3} \mu}{\rho}}$

Persamaan 2 memperlihatkan bahwa Gelombang $P$ dapat menjalar pada medium padat, cair dan gas yang semuanya bersifat dapat dimampatkan $(K \neq 0)$. Sedangkan Gelombang $S$ yang terpolarisasi pada bidang vertikal disebut Gelombang $S V$ dan Gelombang $S$ yang terpolarisasi pada bidang horizontal disebut Gelombang $\mathrm{SH}$.

Persamaan kecepatan gelombang $S$, diberikan sebagai berikut,

$\beta=\sqrt{\frac{\mu}{\rho}}$

Berdasarkan sifat elastisnya, mendefinisikan bahwa kecepatan gelombang $S$ adalah rigiditas atau modulus shear $(\mu)$. Di dalam medium cair dan gas, $\mu$ bernilai 0 dan gelombang $S$ tidak dapat melewatinya

\subsection{Parameter Target}

Parameter target adalah parameter yang berhubungan dengan deskripsi (gambaran) geologi bawah permukaan. Parameter target merupakan masukan awal dalam melakukan desain survei seismik 3D, semakin jelas diskripsi target akan semakin baik pula desain yang dihasilkan. Parameter target tersebut terdiri dari 7 parameter (Cordsen dalam Edy, 2011) yaitu:

\subsubsection{Target Sasaran}

Merupakan lapisan batuan bawah permukaan bumi yang menarik untuk diselidiki dengan menggunkan metode seismik karena diperkirakan memiliki kandungan hidrokarbon yang potensial.

\subsubsection{Kedalaman Obyektif}

Merupakan kedalaman obyektif utama dan kedalaman obyektif sekunder dimana kedua kedalaman tersebut dapat diukur dari peta struktur atau dari penampang seismik sebelumnya.

\subsubsection{Kedalaman Bawah Permukaan}

Merupakan luasan dari batas (horizon) atas dan bawah kedalaman obyek yang membutuhkan penggambaran seismik.

\subsubsection{Kemiringan Target}

Merupakan sudut antara bidang orthogonal terhadap bidang netral. Dip diukur dari peta struktur atau dari penampang seismik sebelumnya.

\subsubsection{Frekuensi}

Merupakan frekuensi maksimum yang diharapkan masih bisa diterima yang terkandung dalam jejak seismik yang diperoleh di lapangan.

\subsubsection{Kecepatan Gelombang}

Kecepatan gelombang yang dimaksud adalah kecepatan interval dimana kecepatan ini diperoleh dari hasil well velocity survey yang dibuat berdasarkan interval kedalaman.

\subsubsection{Cadangan Minyak}

Merupakan cadangan minyak tersisa (total recoverable reserves) suatu lapangan meliputi cadangan terbukti, cadangan mungkin, cadangan boleh jadi dan cadangan potensial EOR (Enhance Oil Recovery).

\subsection{Parameter Akuisisi Seismik}

Parameter akuisisi dalam eksplorasi seismik memiliki pengaruh penting untuk memperoleh kualitas data seismik yang optimal serta memiliki anggaran survei yang efisien. Berikut merupakan beberapa parameter akuisisi seismik tersebut, 


\subsubsection{Kelipatan Liputan}

Fuchsluger, 2011 menyatakan bahwa kelipatan liputan (Fold Coverage) adalah jumlah semua Common Mid Point (CMP), yang ditandai oleh satu bin, karena itu setiap bin memiliki kelipatan liputan yang spesifik. Untuk seismik 3D, kelipatan liputan dapat dirumuskan sebagai berikut,

$F_{\text {stacking }}=F_{i l} x F_{x l}$

Keterangan:

$\begin{array}{ll}F_{\text {stacking }} & : \text { Fold } \text { penuh } \\ F_{\text {il }} & : \text { Fold } \text { arah inline } \\ F_{x l} & : \text { Fold } \text { arah crossline }\end{array}$

Dimana fold arah inline dan fold arah crossline dapat dirumuskan sebagai berikut,

$F_{i l}=\left[\frac{1}{2} *(n R C) *\left(\frac{R L I}{S I}\right)\right]$

$F_{x l}=\left[\frac{1}{2} *(n R L)\right]$

Keterangan:

$n R C \quad$ : Jumlah channel receiver

$R L I \quad$ : Jarak antara lintasan receiver

SI : Jarak antara shot point

$n R L$ : Jumlah lintasan receiver dalam satu template.

\subsubsection{Ukuran Bin}

Ukuran bin dikontrol oleh jarak antara receiver $(R I)$ dan jarak antara source $(S I)$, dimana mereka memiliki ukuran yang sama, sehingga berbentuk kuadrat. $R I$ dan SI mendefifisikan jarak spatial sampling, yang merupakan faktor penting dalam survei seismik. RI dan SI ditentukan pada tahap akuisisi dan tidak akan bisa diperbaiki pada saat pengolahan data. Jarak antara receiver dan source yang kecil sangat menguntungkan dalam semua kasus untuk kualitas data seismik tetapi akan mempengaruhi anggaran survei secara signifikan (Ebrom dalam Fuchsluger, 2011). Ukuran bin dapat dirumuskan sebagai berikut,

$B=\frac{V}{4 * f_{\max } * \sin (\theta)}$
Keterangan:

$V \quad:$ Kecepatan interval atau rms

$f_{\max } \quad$ : Frekuensi maksimum

$\theta \quad$ : Kemiringan reflektor

\subsubsection{Migrasi Aperture}

Migrasi aperture didefinisikan sebagai suatu pinggiran yang harus ditambahkan pada sekeliling area target bawah permukaan dalam memigrasikan targettarget yang miring dengan benar dan memfokuskan dengan benar energi yang terdifraksi pada pinggir area target. Migrasi aperture berhubungan dengan dua aspek teknik migrasi, yaitu memindahkan reflektor miring ke posisi reflektor yang sebenarnya dan menghilangkan difraksi. Batas eksternal migrasi aperture berhubungan dengan area fold yang penuh (Chaouch dan Mari, 2006). Migrasi aperture dapat dirumuskan sebagai berikut,

$M_{a}=Z * \tan \alpha=\left(\frac{V t_{0}}{2}\right) * \tan \alpha$

Keterangan:

$Z \quad$ : Kedalaman target dari permukaan

$V t_{0} \quad$ : Kecepatan target dari permukaan

$\alpha \quad$ : Kemiringan reflektor target.

\subsubsection{Offset Maksimum}

Offset maksimum $\left(X_{\max }\right)$ berhubungan dengan jarak antara titik shot yang aktual dan receiver terjauh dari suatu template. Jadi $X_{\max }$ dapat diperkirakan sebagai setengah dari panjang diagonal template dengan persamaan,

$X_{\text {max }}=\sqrt{\left(X_{\text {cross }}^{2}+X_{\text {in }}^{2}\right)}$

Dimana:

$X_{\text {max }}:$ Offset maksimum

$X_{\text {cross }}$ : Jarak antara titik shot dan lintasan receiver terjauh dalam arah crossline

$X_{\text {in }} \quad$ Jarak antara titik shot dan lintasan receiver terjauh dalam arah inline 


\subsubsection{Offset Minimum}

Offset terpendek pada bin ini adalah offset minimum yang terpanjang dari suatu survei yang disebut $X_{\min }$ (Gambar 28) atau dapat disesuaikan dengan diagonal dari suatu box. $X_{\min }$ pada desain orthogonal, brick, dan zigzag ditentukan dengan,

$X_{\text {min }}=\sqrt{R_{y}^{2}+S_{x}^{2}}$

Dimana:

$X_{\text {min }}:$ Offset minimum maksimum

$R_{y} \quad$ : Jarak antara lintasan receiver

$S_{x} \quad$ : Jarak antara lintasan source

\subsubsection{Panjang Perekaman}

Menurut Chaouch dan Mari, 2006 bahwa panjang perekaman dipilih berdasarkan two way time (TWT) dari lapisan terdalam dari zona target karena waktu migrasi aperture untuk mengecilkan difraksi dihasilkan oleh formasi yang terdalam, perubahan statik dan pengolahan data yang dibutuhkan. Panjang perekaman harus disesuaikan dengan waktu target yang diperlukan agar menghindari peningkatan yang kurang bermanfaat dari panjang durasi survei.

\subsubsection{Laju Pencuplikan}

Laju pencuplikan akan menentukan batas frekuensi maksimum yang masih dapat direkam dan direkontruksikan dengan benar sebagai data. Frekuensi yang lebih besar dari batas maksimum akan mengakibatkan timbulnya aliasing. Batas maksimum tersebut, yaitu frekuensi Nyquist. Pada umumnya sinyal frekuensi tinggi dicuplik dengan laju pencuplikan 2 $\mathrm{ms}$ atau $1 \mathrm{~ms}$ agar terhindar dari alias (Sismanto, 1996). Frekuensi Nyquist dihitung dengan persamaan,

$f_{q}=\frac{1}{2 \Delta t}$

Dimana:

$f_{q} \quad$ : Frekuensi Nyquist $(\mathrm{Hz})$

$\Delta t \quad$ : Laju pencuplikan (s)

\subsubsection{Konfigurasi Bentangan}

Penentuan konfigurasi bentangan receiver dan source berdasarkan pada tujuan survei dan kemudahan di lapangan. Beberapa tipe bentangan (spread) pada seismik 3D diantaranya; stright line/orthogonal, brick dan slanted. Pemahaman mengenai geometri orthogonal merupakan hal yang mendasar. Karena baik desain template maupun desain spread (brick, slanted, zigzag) merupakan turunan atau modifikasi dari geometri orthogonal (Cordsen dalam Andita, 2013).

\subsubsection{Ukuran Template}

Pemisahan yang jelas antara survei dengan template wide-azimuth dan template narrow-azimuth dibuat berdasarkan aspek rasio dari template perekaman. Aspek rasio didefinisikan sebagai perbandingan dimensi crossline dengan dimensi inline pada template. Template perekaman dengan aspek rasio < 0.5, tergolong sebagai Narrow-Azimuth. Sedangkan template perekaman dengan aspek rasio $>0.5$, tergolong sebagai WideAzimuth (Cordsen dalam Andita, 2013).

\subsubsection{Ukuran Sumber}

Ukuran sumber (dynamit, tekanan pada air gun, water gun, dll) merupakan ukuran energi yang dilepaskan oleh sumber seismik. Sumber yang terlalu kecil jelas tidak mampu mencapai target yang dalam, sedangkan ukuran sumber yang terlalu besar dapat merusak data dan sekaligus meningkatkan noise. Oleh karena itu, diperlukan ukuran sumber yang optimal melalui test charge (Sismanto, 1996).

\subsubsection{Kedalaman Sumber}

Sumber sebaiknya ditempatkan dibawah lapisan lapuk, sehingga energi sumber dapat ditransfer optimal masuk ke dalam sistem lapisan medium dibawahnya. Untuk mengetahui ketebalan lapisan lapuk dapat diperoleh dari hasil survei seismik 
refraksi atau up hole survey (Sismanto, 1996).

\subsection{Ray Tracing}

Ray tracing (jejak gelombang) merupakan perhitungan cepat untuk penyelesaian persamaan gelombang penuh dan perkiraan untuk gelombang dengan energi tinggi berulangkali. Asumsi ini cukup memadai untuk banyak penerapan seismik. Dasar dari ray tracing adalah persamaan Eikonal, dimana berasal dari persamaan gelombang skalar (Schurr dalam Fuchsluger, 2011).

Persamaan Eikonal dapat ditransformasikan dari fungsi penjalaran waktu ke fungsi penjalaran sinar gelombang (persamaan ray tracing kedua):

$\frac{d \vec{p}}{d s}=\frac{d}{d \vec{s}}\left(\frac{1}{v(\vec{x})} * \frac{d \vec{x}}{d \vec{s}}\right)=\vec{\nabla}\left(\frac{1}{v(\vec{x})}\right)$

Ray tracing bertujuan untuk menyelesaiakan persamaan deferensial untuk mendapatkan sinar gelombang untuk fungsi kecepatan yang berubah-ubah. Secara umum, perhitungan ini diselesaikan dengan finite differences (Yang, 2003).

\section{METODOLOGI PENELITIAN}

\subsection{Alat dan Bahan}

Adapun alat dan bahan dari penelitian ini adalah sebagai berikut:

1. Laptop

2. Software Omni 3D Design and Modelling v. 12.00

3. Software Global Mapper v. 15.00

4. Software ArcGIS v.10.1

\subsection{Prosedur Penelitian}

\subsubsection{Parameter Target dan Model Geologi}

Pemodelan geologi bawah permukaan daerah survei berdasarkan parameter target yang diketahui dari survei seismik dan geologi sebelumnya. Adapun informasi yang diperoleh dari parameter target tersebut adalah kecepatan interval ( $\mathrm{V}-\mathrm{Pi}$ dan $V-S i$, densitas, frekuensi dominan, kedalaman dan struktur setiap perlapisan. Kemudian dari data parameter target tersebut dibuat model geologi 3D bawah permukaan.

\subsubsection{Evaluasi Teknis dan Parameter Akuisisi}

Penentuan parameter akuisisi dilakukan untuk mendapatkan parameter akuisisi yang sesuai dengan target. Parameter akuisisi diperoleh dari evalusi teknis parameter target berdasarkan data geologi dan data seismik sebelumnya.

\subsubsection{Penentuan Konfigurasi Bentangan Ideal}

Pada penentuan konfigurasi bentangan ideal ini menggunakan empat model konfigurasi bentangan yaitu orthogonal, brick, zigzag dan slanted secara teoritis. Dimana keempat konfigurasi bentangan ini menggunakan parameter geofisika yang sama namun penerapan bentangan rangkaian geophone yang berbeda.

\subsubsection{Simulasi Rekaman Konfigurasi Bentangan Ideal}

Hasil dari keempat konfigurasi bentangan ideal tersebut selanjutnya akan dilakukan simulasi rekaman. Simulasi rekaman yang dilakukan, yaitu simulasi distribusi fold, offset dan azimuth serta analisis ilumination (fold migrated) berdasarkan konsep ray tracing.

\subsubsection{Analisis Hasil Simulasi Rekaman Konfigurasi Bentangan Ideal}

Berdasarkan hasil analisis simulasi rekaman maka akan diperoleh kualitas data seismik teoritis dari masing-masing konfigurasi bentangan dan selanjutnya dari analisis ini akan ditentukan satu konfigurasi dan template yang akan dipilih untuk diterapkan pada lapangan survei. 


\subsubsection{Penentuan Bentangan Rill \\ Konfigursai}

Konfigurasi bentangan rill diterapkan berdasarkan konfigurasi bentangan ideal yang telah dipilih. Pada konfigurasi ini akan diasosiasikan dengan kondisi atau halangan (obstacle) di lapangan.

\subsubsection{Simulasi Rekaman Konfigurasi Bentangan Rill}

Simulasi rekaman yang dilakukan sama halnya dengan simulasi rekaman konfigurasi bentangan ideal sebelumnya yaitu simulasi distribusi fold, offset dan azimuth serta analisis ilumination (fold migrated) berdasarkan ray tracing.

\subsubsection{Analisis Hasil Simulasi Rekaman Konfigurasi Bentangan Rill}

Hasil simulasi rekaman bentangan rill dilakukan analisis untuk melihat kualitas datanya. Jika hasil simulasi rekaman menunjukakan kualitas data yang belum mencapai target secara efisien maka bentangan rangkaian geophone dilakukan teknik undershooting sampai memperoleh kualitas data yang bagus dan tetap mencapai target sasaran.

\section{HASIL DAN PEMBAHASAN}

\subsection{Parameter Target dan Pemodelan Geologi}

Parameter target diperoleh dari hasil survei geologi dan seismik sebelumnya. Parameter Target Lapangan RL dapat dilihat pada Tabel 1. Dari parameter target yang telah diketahui, maka dapat dilakukan pemodelan geologi secara 3D Gambar 1.

Beradasarkan evaluasi teknis sebelumnya, yang menjadi kedalaman bawah permukaan yang membutuhkan gambaran seismik 3D yaitu berkisar dari kedalaman 500-2800 m bawah permukaan dengan target lapisan obyektif utama pada Formasi 3 dan lapisan obyektif sekunder pada formasi 4 dan Basement.

\subsection{Evaluasi Teknis Parameter Target}

Evaluasi teknis yang dilakukan yaitu dengan cara melakukan analisis terhadap model geologi atau formasi geologi yang menjadi target sasaran. Adapun analisis yang dilakukan, yaitu analisis ukuran bin, offset dan migrasi aperture pada reflektor atau horizon target.

Berdasarkan analisis yang dilakukan diperoleh kisaran ukuran bin terkecil pada lapisan target berkisar dari 12,4-14,5 m, offset terdekat $\left(X_{\text {min }}\right)$ yang berkisar dari 497,6-830,3 m dan offset terjauh $\left(X_{\max }\right)$ berkisar dari 1077,9-2281,7 $\mathrm{m}$ atau lebih, dan migrasi aperture yang diterapkan berkisar 600-1000 m.

\subsection{Penentuan Parameter Akuisisi}

Dari evaluasi teknis yang telah dilakukan maka diperoleh parameter hasil evaluasi teknis yang optimal, yaitu ukuran bin minimum $10 \mathrm{~m}$, offset terdekat berkisar 497,6-830,3 m, offset terjauh berkisar 1077,9-2281,7 m dan migrasi aperture berkisar $600 \mathrm{~m}$.

Berdasarkan hasil evaluasi teknis yang telah dilakukan, maka dapat ditentukan parameter akuisisi yang optimal pada Lapangan RL Tabel 2.

\subsection{Penerapan Konfigurasi Bentangan Ideal}

Pada penelitian ini diterapkan empat model konfigurasi bentangan ideal, yaitu orthogonal, brick, zig-zag dan slanted. Pertimbangan pemilihan konfigurasi bentangan ini berdasarkan kualitas data seismik berdasarkan penyebaran fold pada masing-masing lapisan target (seismik illumination) dan juga berdasarkan efisiensi anggaran survei yang ditentukan berdasarkan jumlah source yang digunakan di Lapangan RL.

Dari konfigurasi bentangan dan tipe template yang diterapkan, maka diperoleh konfigurasi bentangan ideal orthogonal memiliki source sejumlah 10092 titik dan receiver sejumlah 21000 titik Gambar 2, konfigurasi bentangan ideal brick ini 
memiliki source sejumlah 9924 titik dan receiver sejumlah 21000 titik Gambar 3, konfigurasi bentangan ideal zig-zag ini memiliki source sejumlah 9744 titik dan receiver sejumlah 21000 titik Gambar 4, dan pada konfigurasi bentangan ideal slanted ini memiliki source sejumlah 9744 titik dan receiver sejumlah 21000 titik Gambar 5.

\subsection{Simulasi dan Analisis Rekaman Konfigurasi Bentangan Ideal}

Pada konfigurasi bentangan ideal ini simulasi dan analisis rekaman dibagi atas dua template, yaitu narrow dan wide azimuth. Dari masing-masing template ini akan dilakukan simulasi rekaman berdasarkan penyebaran fold migrated (illumination) pada masing-masing konfigurasi bentangan di zona target.

Dari hasil simulasi rekaman konfigurasi bentangan ideal orthogonal dengan model template wide azimuth Gambar 6 dan model template narrow azimuth Gambar 7, konfigurasi bentangan ideal brick dengan model template wide azimuth Gambar 8 dan model template narrow azimuth Gambar 9, konfigurasi bentangan ideal zig-zag dengan model template wide azimuth Gambar 10 dan model template narrow azimuth Gambar 11, dan konfigurasi bentangan ideal slanted dengan model template wide azimuth Gambar 12 dan model template narrow azimuth Gambar 13 dapat dilihat secara statistik pada Tabel 3 dan Tabel 4.

Dari keseluruhan model konfigurasi dan ukuran azimuth yang diterapkan dapat dianalisis bahwa pada zona patahan curam dan cekungan (struktur sinklin) sempit memiliki variasi fold semakin sedikit dibandingkan pada zona antiklin, hal ini disebabkan karena difraksi gelombang akibat struktur yang tidak rata sehingga pemantulan gelombang menjadi tidak teratur. Kemudian pada distribusi fold, semakin ke bawah permukaan distribusi fold semakin berkurang atau tidak merata, hal ini disebabkan sinyal pantul gelombang tidak terekam dipermukaan, maka untuk mengatasinya diperlukan bentangan offset yang lebih luas dan ukuran bin yang lebih kecil untuk mencuplik struktur yang komplek.

Berdasarkan penjelasan Tabel 5 dan Tabel 6, maka konfigurasi yang akan diterapkan pada Lapangan RL, yaitu konfigurasi bentangan ideal orthogonal model template narrow azimuth dengan pertimbangannya bahwa pada konfigurasi bentangan ini memiliki penyebaran fold pada bin yang lebih merata pada masingmasing lapisan target, meskipun secara anggaran survei masih kurang efisien.

\subsection{Penerapan Konfigurasi Bentangan Rill}

Pada konfigurasi bentangan rill ini dibutuhkan peta obstacle (halangan) untuk merealisasikan desain survei seismik sesuai dengan kondisi lapangan.

Untuk mengatasi zona obstacle maka dilakukan teknik undershooting pada konfigurasi bentangan dimana titik source telah dipindahkan di sekeliling zona obstacle Gambar 14. Dengan menggunakan teknik ini dapat dilihat, bahwa terjadi pengurangan jumlah receiver dari 21000 menjadi 19939, sedangkan jumlah source tetap.

\subsection{Simulasi dan Analisis Rekaman Konfigurasi Bentangan Rill}

Berdasarkan hasil simulasi dan analisis rekaman pada konfigurasi bentangan rill, dapat dilihat bahwa kualitas data seismik atau penyebaran fold pada lapisan target (illumination) akan berkurang dengan adanya obstacle pada suatu lapangan Gambar 15, namun meskipun demikian masih dapat dilakukan optimalisasi terhadap penyebaran fold pada zona tareget dengan cara melakukan pemindahan titik source (teknik undershooting) setepat mungkin, sehingga tetap menghasilkan kualitas data yang tinggi dengan penyebaran bin yang memiliki fold yang merata, meskipun fold dalam bin-nya berkurang. Setelah konfigurasi 
bentangan rill diterapkan, maka diperoleh Peta Desain Survei Seismik 3D Darat yang optimal pada Lapangan RL.

\section{KESIMPULAN DAN SARAN}

\subsection{Kesimpulan}

Adapun kesimpulan dari penelitian ini sebagai berikut:

1. Parameter desain survei seismik 3D darat yang optimal pada Lapngan RL memiliki ukuran jarak anatara receiver $20 \mathrm{~m}$, jarak antara source $40 \mathrm{~m}$, jarak antara lintasan receiver $480 \mathrm{~m}$, jarak anatara lintasan source $500 \mathrm{~m}$, ukuran template 12 lintasan x 350 channel (wide azimuth) dan 10 lintasan $\times 450$ channel (narrow azimuth).

2. Konfigurasi bentangan orthogonal dengan tipe template narrow azimuth merupakan konfigurasi bentangan yang paling optimal pada Lapangan RL, karena memiliki penyebaran fold pada bin (populasi bin) yang lebih banyak dan merata pada lapisan target, meskipun secara anggaran survei belum begitu efisien.

3. Pada zona patahan dan sinklin yang curam pada lapisan target tidak memiliki penyebaran fold yang merata karena titik pantul gelombang di zona tersebut tidak terekam pada receiver aktif di permukaan, sehingga dibutuhkan ukuran bin yang lebih kecil dan offset yang lebih luas.

4. Teknik undershooting (shot point recovery) atau pemindahan titik source dapat dilakukan untuk mengatasi pengurangan fold coverage pada lapisan target akibat adanya zona obstacle di permukaan.

\subsection{Saran}

Saran untuk penelitian selanjutnya agar informasi parameter target harus lebih lengkap dan detail mencakup informasi geologi dan geofisika sebelumnya agar proses desain survei seismik 3D selanjutnya mendapat hasil yang lebih optimal.

\section{DAFTAR PUSTAKA}

Andita, K. 2013. Geometri Brick pada Desain Survei Seismik Darat 3D di Lapangan $X$. http://seismixplorer.blogspot.co.id/201 3/06/geometri-brick-pada-desainsurvey.html. Diakses pada tanggal 28 Agustus 2017.

Ashton, C. P., Bacon, B., Deplante, C., Dickilreson dan Redekop, G. 1994. 3D Seismic Survey Design. Oilfield Review. Vol. 6. No. 2.

Chaouch, A. dan Mari, J. L. 2006. 3D Land Seismic Survey: Definition of Geophysical Parameter. Jurnal Oil \& Gas Science and Technology Rev. IFP. Vol. 61. No. 5.

Cordsen, A. 2000. Planning Land 3D Seismic Survey. Society of Exploration Geophysicists. Tulsa.

Edi, S. S. 2011. Kajian Desain Survei Seismik 3 Dimensi pada Lapangan X Jawa Barat. Tesis Pascasarjana FMIPA UI.

Fuchsluger, M. 2011. 3D Model Based Acquisition Design for The Seismic Exploration of Deep Vienna Basin. Tesis Pascasarjana Universitas Wien.

Koesoemadinata, R. P. 1980. Geologi Minyak dan Gas Bumi Jilid I Edisi 2. Penerbit ITB. Bandung.

Lowrie, W. 2007. Fundamental of Geophysics $2^{\text {nd }}$. Cambridge University Press. New York.

Munadi, S. 2000. Aspek Fisis Seismologi Eksplorasi. Program Studi Geofisika, Jurusan Fisika FMIPA UI. Depok.

Sheriff, R. E. dan Geldart, I. P. 1995. Exploration Seismology Second Edition. Cambridge University Press. New York.

Sismanto. 1996. Akuisisi dan Pengolahan Data Seismik. UGM. Yogyakarta.

Yang, W. 2003. A Basical Study on Twopoint Seismic Ray Tracing. http://www.ees.nmt.edu/Geop/Classes /GEOP523?Docs/yang.pdf. Diakses pada tanggal 29 Agustus 2017. 


\section{LAMPIRAN}

Tabel 1. Parameter Target Lapangan RL

\begin{tabular}{|l|l|l|l|l|l|}
\hline & Formasi 1 & Formasi 2 & Formasi 3 & Formasi 4 & Basement \\
\hline Vp $(\mathrm{m} / \mathrm{s})$ & 1800 & 2200 & 3000 & 2400 & 4600 \\
\hline Vs $(\mathrm{m} / \mathrm{s})$ & 600 & 1000 & 1300 & 1200 & 2300 \\
\hline$\rho(\mathrm{gr} / \mathrm{cc})$ & 1.8 & 2.2 & 2.5 & 2.3 & 2.7 \\
\hline$f_{\text {dom }}(\mathrm{Hz})$ & \multicolumn{5}{|c|}{50} \\
\hline Dip & $\pm 25^{0}$ & $\pm 30^{0}$ & $\pm 45^{0}$ & $\pm 45^{0}$ & $\pm 45^{0}$ \\
\hline Resolusi & \multicolumn{5}{|c|}{ Struktur dan Stratigrafi } \\
\hline Litologi & $\begin{array}{l}\text { Batu Pasir } \\
\text { dan } \\
\text { Lempung }\end{array}$ & $\begin{array}{l}\text { Lempung, } \\
\text { Pasir, } \\
\text { Serpih }\end{array}$ & $\begin{array}{l}\text { Gamping } \\
\text { Terumbu, } \\
\text { Sisipan } \\
\text { Serpih dan } \\
\text { Napal }\end{array}$ & $\begin{array}{l}\text { Batu pasir } \\
\text { selingan } \\
\text { serpih }\end{array}$ & $\begin{array}{l}\text { Batuan } \\
\text { Beku }\end{array}$ \\
\hline
\end{tabular}

Tabel 2. Parameter Akuisisi Seismik 3D Darat Lapangan RL

\begin{tabular}{|l|l|l|}
\hline \multicolumn{1}{|c|}{ Parameter Akuisisi } & \multicolumn{2}{|c|}{ Satuan } \\
\hline$R_{x}$ & $20 \mathrm{~m}$ \\
\hline$S_{y}$ & $40 \mathrm{~m}$ \\
\hline$R_{y}$ & $480 \mathrm{~m}$ \\
\hline$S_{x}$ & $500 \mathrm{~m}$ \\
\hline$X_{\min }$ & $693 \mathrm{~m}$ \\
\hline Salvo & $12 \mathrm{shot}$ \\
\hline Jenis Sumber & Explosive \\
\hline Ukuran Sumber & $1-3 \mathrm{~kg}$ & \multicolumn{1}{|c|}{ Narrow Azimuth } \\
\hline Kedalaman Sumber & $25-30 \mathrm{~m}$ & $4874,09 \mathrm{~m}$ \\
\hline \multicolumn{1}{|c|}{ Template } & \multicolumn{1}{|c|}{ Wide Azimuth } & 10 line \\
\hline$X_{\text {max }}$ & $4227,34 \mathrm{~m}$ & 450 receiver/line \\
\hline$n R L \quad$ & 12 line & 4500 receiver \\
\hline$n R$ & 350 receiver/line & 45 \\
\hline channel & 4200 receiver & $1720 \mathrm{~m}$ \\
\hline Full Fold Coverage & 42 & $1000 \mathrm{~m}$ \\
\hline Inline Taper & $1460 \mathrm{~m}$ & \\
\hline Crossline Taper & $1200 \mathrm{~m}$ & \\
\hline
\end{tabular}

Tabel 3. Statistik Data Hasil Analisis Simulasi Rekaman Konfigurasi Bentangan Ideal Formasi 3

\begin{tabular}{|c|c|c|c|c|}
\hline $\begin{array}{c}\text { Konfigurasi } \\
\text { Bentangan }\end{array}$ & $\begin{array}{c}\text { Fold } \\
\text { Minimum }\end{array}$ & $\begin{array}{c}\text { Fold } \\
\text { Maksimum }\end{array}$ & $\begin{array}{c}\text { Jumlah } \\
\text { Populasi Bin }\end{array}$ & $\begin{array}{c}\text { Total Number } \\
\text { of Traces }\end{array}$ \\
\hline Ortho WA & 1 & 714 & 958077 & 30805578 \\
\hline Ortho NA & 1 & 996 & 958026 & 32084589 \\
\hline Brick WA & 1 & 771 & 957631 & 30499051 \\
\hline Brick NA & 1 & 990 & 957423 & 31750303 \\
\hline Zig-zag WA & 1 & 772 & 950975 & 30175294 \\
\hline Zig-zag NA & 1 & 995 & 950293 & 31399439 \\
\hline Slanted WA & 1 & 768 & 948630 & 30177731 \\
\hline Slanted NA & 1 & 995 & 947665 & 31399929 \\
\hline
\end{tabular}


Tabel 4. Satistik Data Hasil Analisis Simulasi Rekaman Konfigurasi Bentangan Ideal Formasi 4

\begin{tabular}{|c|c|c|c|c|}
\hline $\begin{array}{c}\text { Konfigurasi } \\
\text { Bentangan }\end{array}$ & $\begin{array}{c}\text { Fold } \\
\text { Minimum }\end{array}$ & $\begin{array}{c}\text { Fold } \\
\text { Maksimum }\end{array}$ & $\begin{array}{c}\text { Jumlah } \\
\text { Populasi Bin }\end{array}$ & $\begin{array}{c}\text { Total Number } \\
\text { of Traces }\end{array}$ \\
\hline Ortho WA & 1 & 1271 & 909462 & 30805578 \\
\hline Ortho NA & 1 & 1550 & 915233 & 31253926 \\
\hline Brick WA & 1 & 1564 & 908608 & 29626174 \\
\hline Brick NA & 1 & 1521 & 914170 & 30919984 \\
\hline Zig-zag WA & 1 & 1245 & 902998 & 29305124 \\
\hline Zig-zag NA & 1 & 1604 & 908109 & 30569627 \\
\hline Slanted WA & 1 & 1243 & 901389 & 29305061 \\
\hline Slanted NA & 1 & 1576 & 906198 & 30567792 \\
\hline
\end{tabular}

Keterangan: NA = Narrow Azimuth dan WA = Wide Azimuth

Tabel 5. Parameter Konfigurasi Bentangan Optimal pada Formasi 3

\begin{tabular}{|c|c|c|c|c|c|c|c|c|}
\hline & OWA & ONA & BWA & BNA & ZWA & ZNA & SWA & SNA \\
\hline $\begin{array}{c}\text { Fold } \\
\text { Maksimum }\end{array}$ & & & & & & & & \\
\hline $\begin{array}{c}\text { Jumlah } \\
\text { Populasi } \\
\text { Bin }\end{array}$ & & & & & & & & \\
\hline $\begin{array}{c}\text { Total } \\
\text { Jumlah } \\
\text { Trace }\end{array}$ & & & & & & & & \\
\hline $\begin{array}{c}\text { Fold } \\
\text { Tertinggi } \\
\text { pada Zona } \\
\text { Hole }\end{array}$ & & & & & & & & \\
\hline $\begin{array}{c}\text { Harga } \\
\text { berdasarkan } \\
\text { Source }\end{array}$ & & & & & & & & \\
\hline $\begin{array}{c}\text { Harga } \\
\text { berdasarkan } \\
\text { Receiver } \\
\text { Aktif }\end{array}$ & & & & & & & & \\
\hline Total Poin & 2 & 2 & 1 & 0 & 2 & 1 & 2 & 2 \\
\hline
\end{tabular}


Tabel 6. Parameter Konfigurasi Bentangan Optimal pada Formasi 4

\begin{tabular}{|c|c|c|c|c|c|c|c|c|}
\hline & OWA & ONA & BWA & BNA & ZWA & ZNA & SWA & SNA \\
\hline $\begin{array}{c}\text { Fold } \\
\text { Maksimum }\end{array}$ & & & & & & & & \\
\hline $\begin{array}{c}\text { Jumlah } \\
\text { Populasi Bir }\end{array}$ & & & & & & & & \\
\hline $\begin{array}{c}\text { Total Jumlal } \\
\text { Trace }\end{array}$ & & & & & & & & \\
\hline $\begin{array}{c}\text { Fold } \\
\text { Tertinggi } \\
\text { pada Zona } \\
\text { Hole }\end{array}$ & & & & & & & & \\
\hline $\begin{array}{c}\text { Harga } \\
\text { berdasarkan } \\
\text { Source }\end{array}$ & & & & & & & & \\
\hline $\begin{array}{c}\text { Harga } \\
\text { berdasarkan } \\
\text { Receiver } \\
\text { Aktif }\end{array}$ & & & & & & & & \\
\hline Total Poin & 1 & 2 & 2 & 0 & 2 & 3 & 2 & 1 \\
\hline
\end{tabular}

Keterangan: $\mathrm{O}=$ Orthogonal, $\mathrm{B}=$ Brick, $\mathrm{Z}=$ Zig-zag, $\mathrm{S}=$ Slanted, $\mathrm{NA}=$ Narrow Azimuth, WA = Wide Azimuth dan Warna kuning = terunggul 


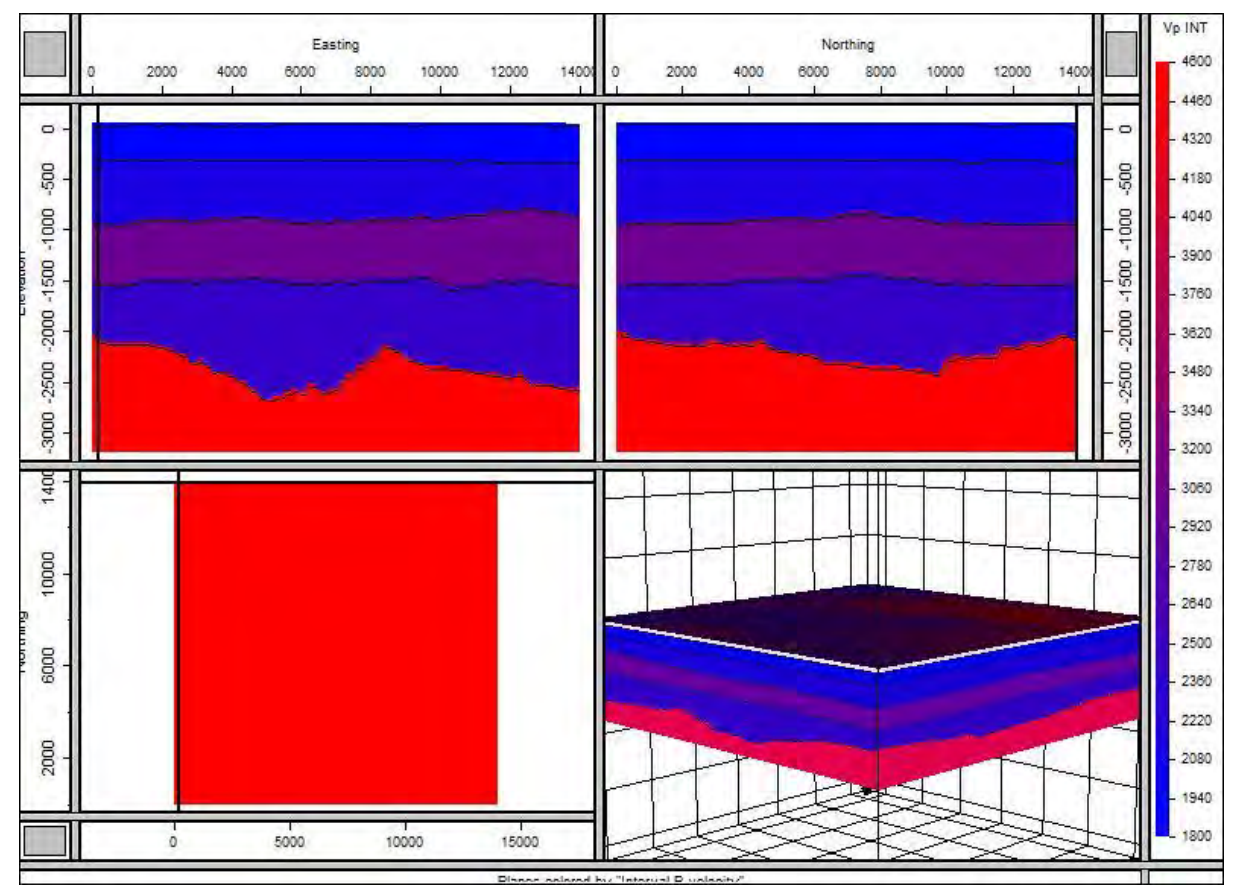

Gambar 1. Model Geologi 3D Lapangan RL

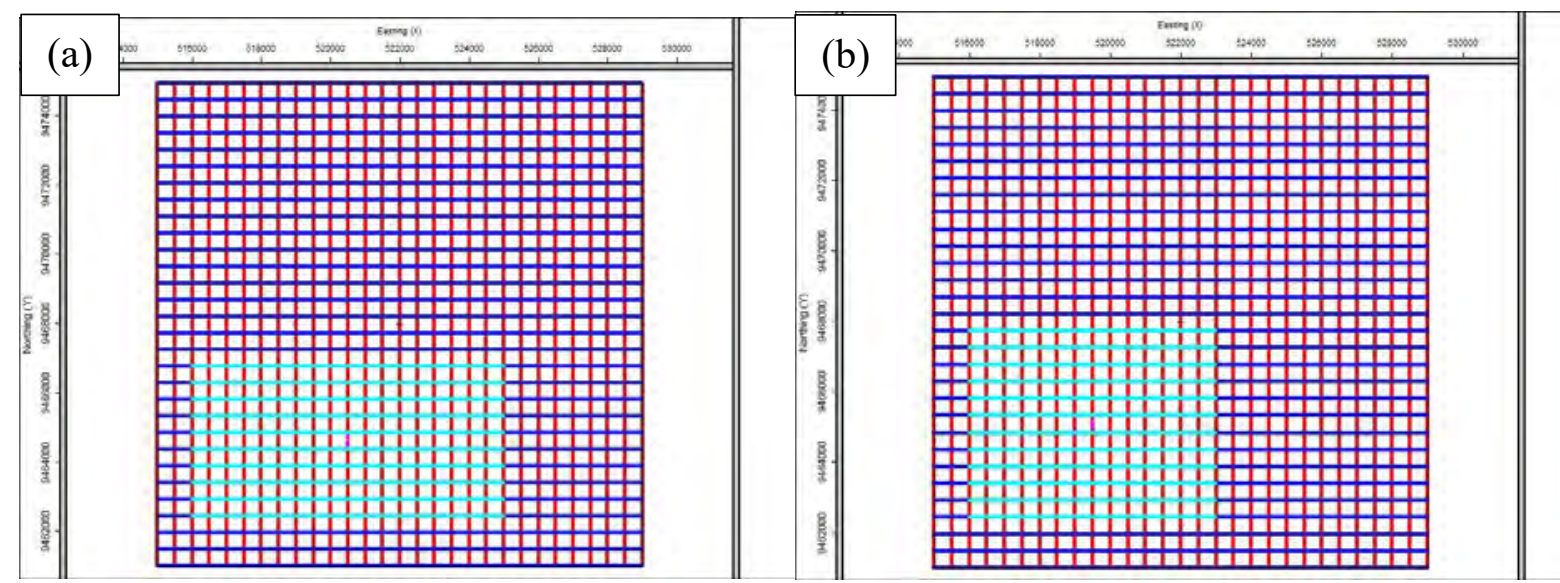

Gambar 2. Bentangan Konfigurasi Ideal Orthogonal, (a). Template Narrow azimuth dan (b). Template Wide azimuth

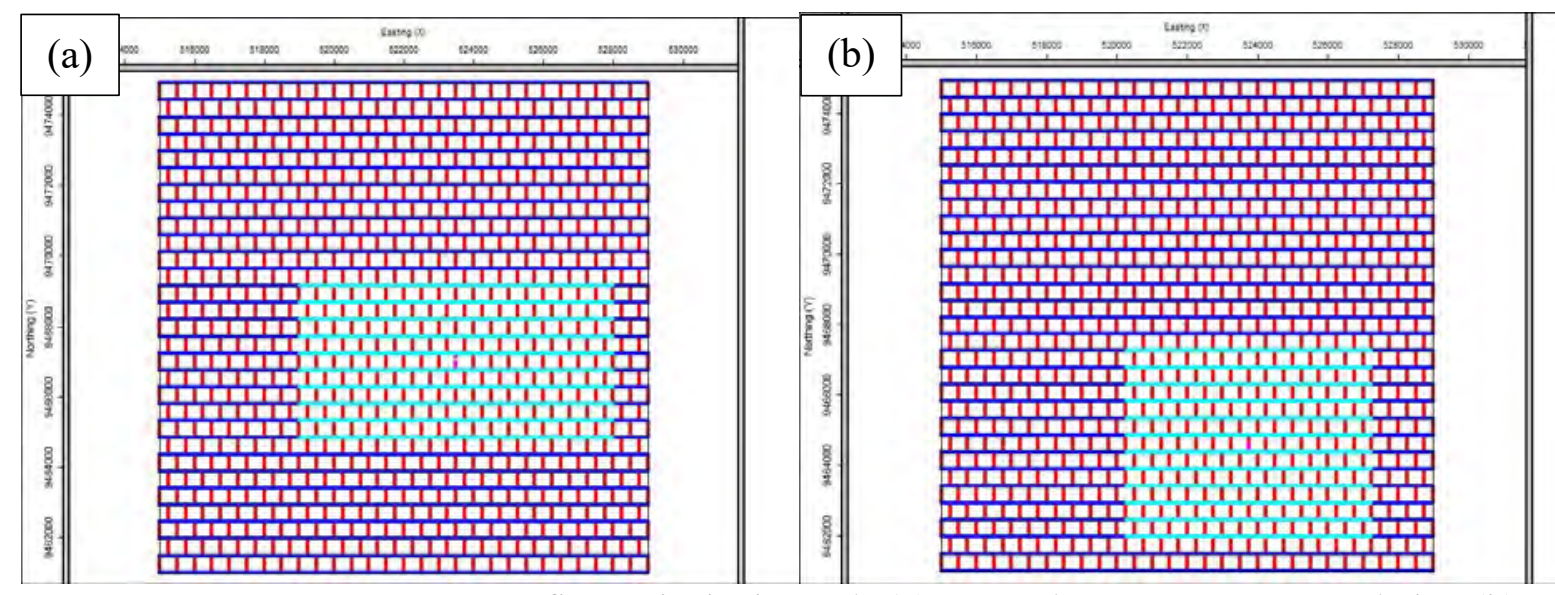

Gambar 3. Bentangan Konfigurasi Ideal Brick, (a). Template Narrow azimuth dan (b). Template Wide azimuth 

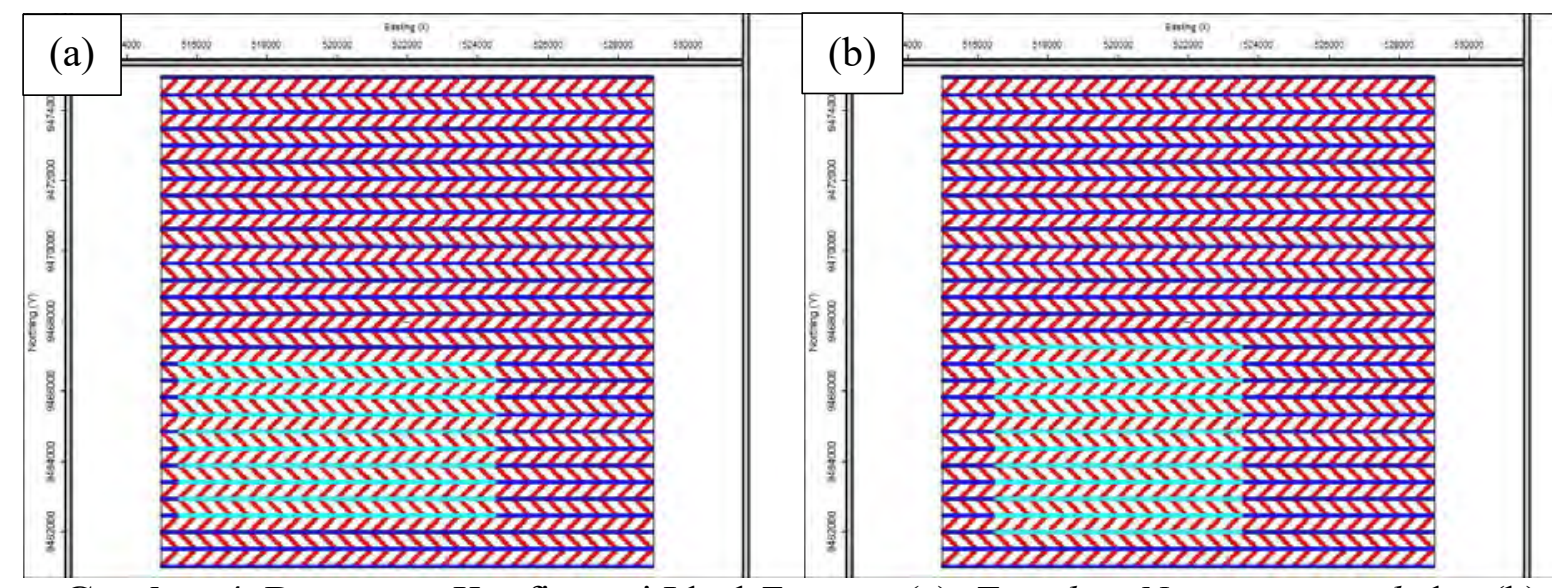

Gambar 4. Bentangan Konfigurasi Ideal Zig-zag, (a). Template Narrow azimuth dan (b). Template Wide azimuth
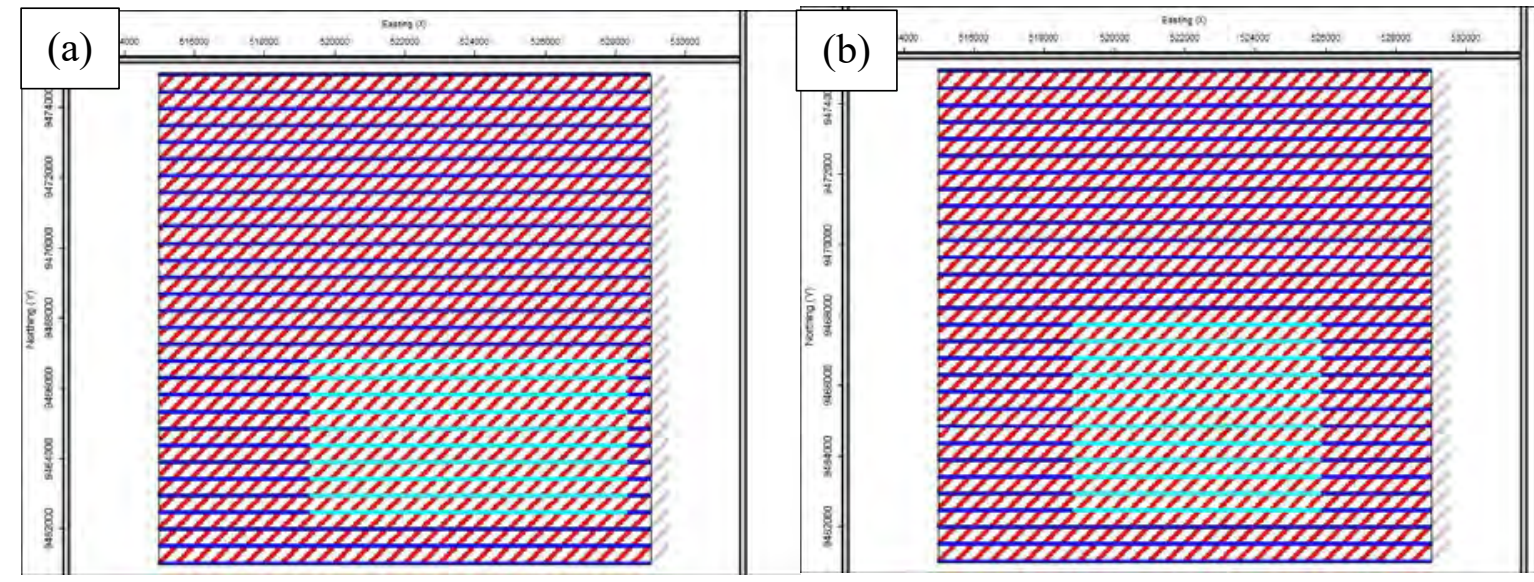

Gambar 5. Bentangan Konfigurasi Ideal Slanted, (a). Template Narrow azimuth dan (b). Template Wide azimuth

Keterangan: Lintasan berwarna merah $=$ Source

Lintasan berwarna biru tua $=$ Receiver

Lintasan berwarna biru muda $=$ Template

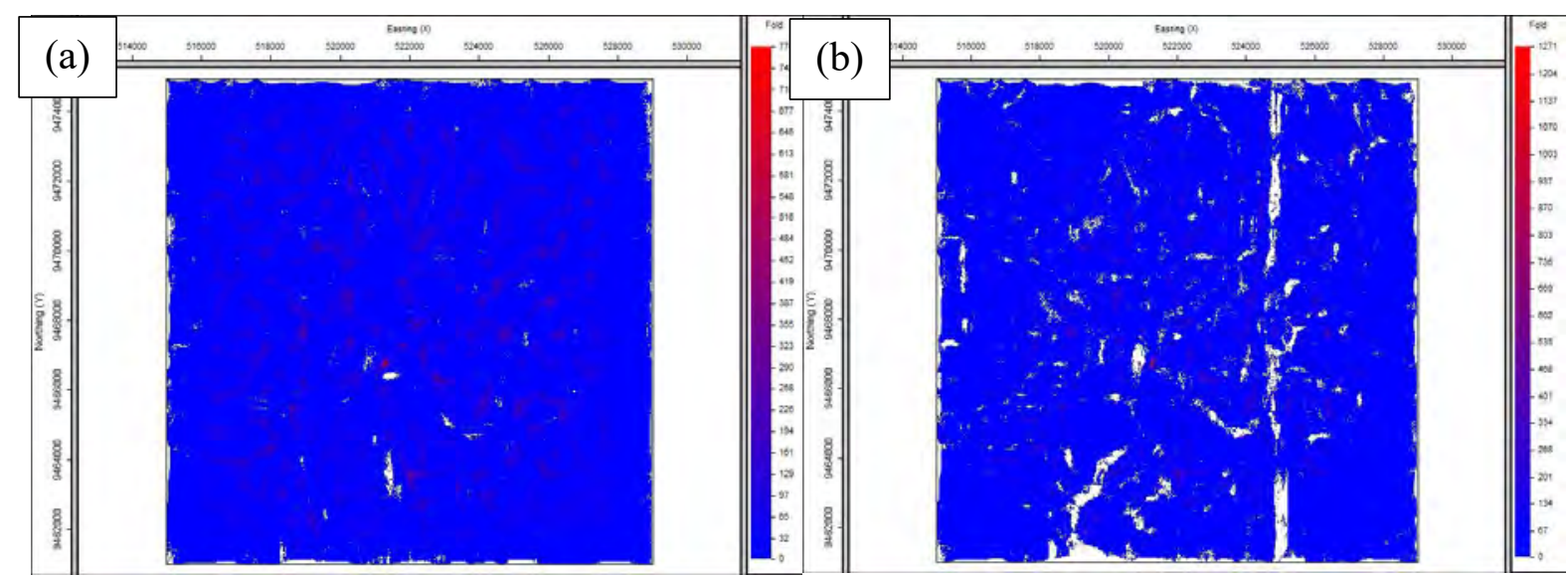

Gambar 6. Distribusi Fold Migrated (illumination) Konfigurasi Bentangan Orthogonal Template Wide Azimuth, (a). Formasi 3 dan (b). Formasi 4 


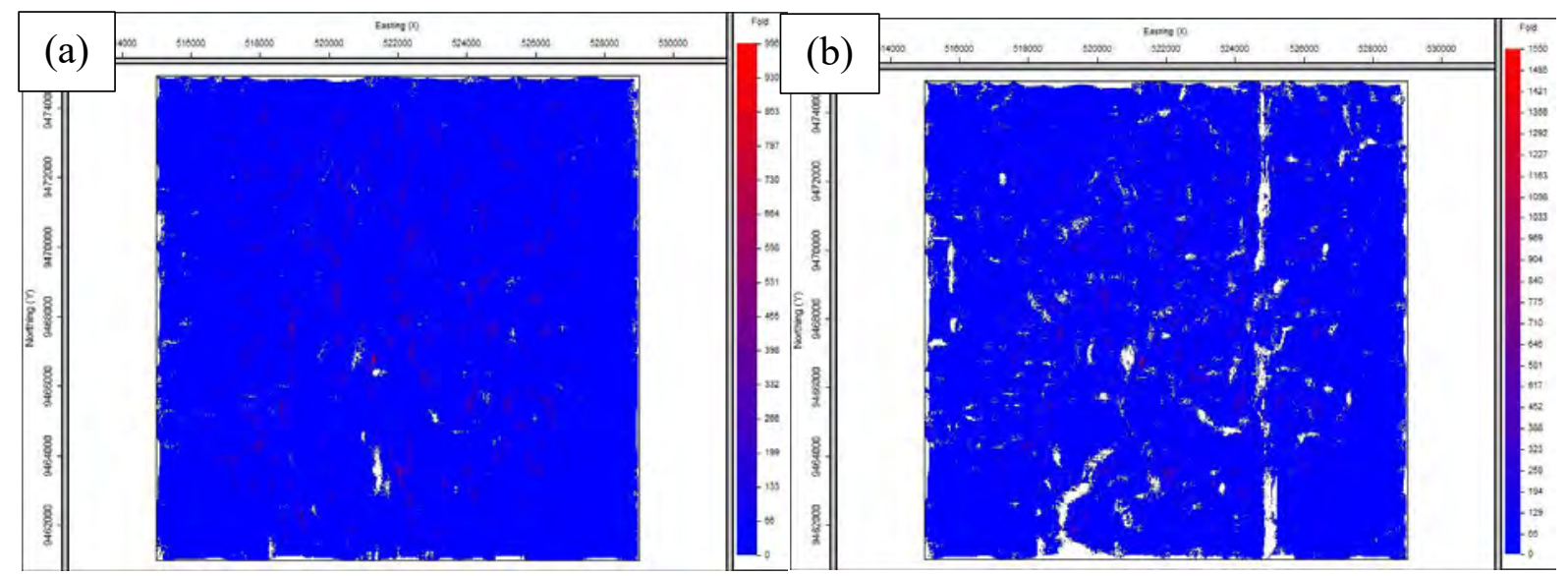

Gambar 7. Distribusi Fold Migrated (illumination) Konfigurasi Bentangan Orthogonal Template Narrow Azimuth, (a). Formasi 3 dan (b). Formasi 4

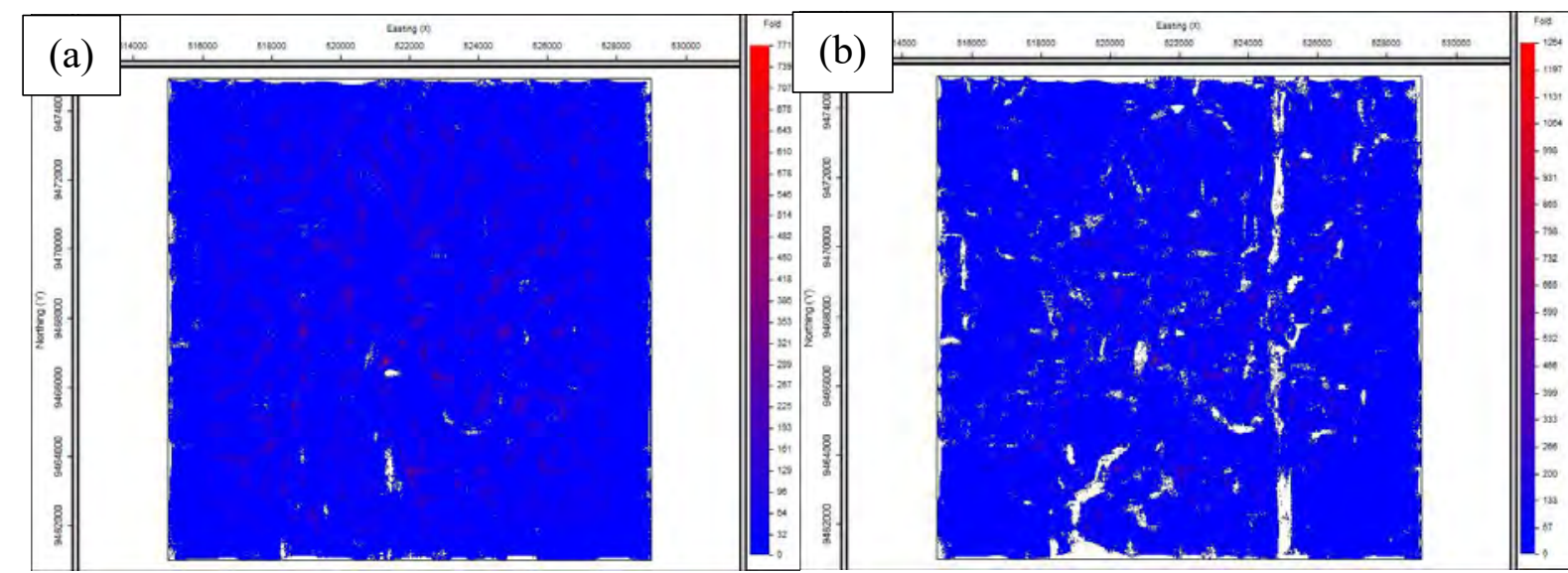

Gambar 8. Distribusi Fold Migrated (illumination) Konfigurasi Bentangan Brick Template Wide Azimuth, (a). Formasi 3 dan (b). Formasi 4

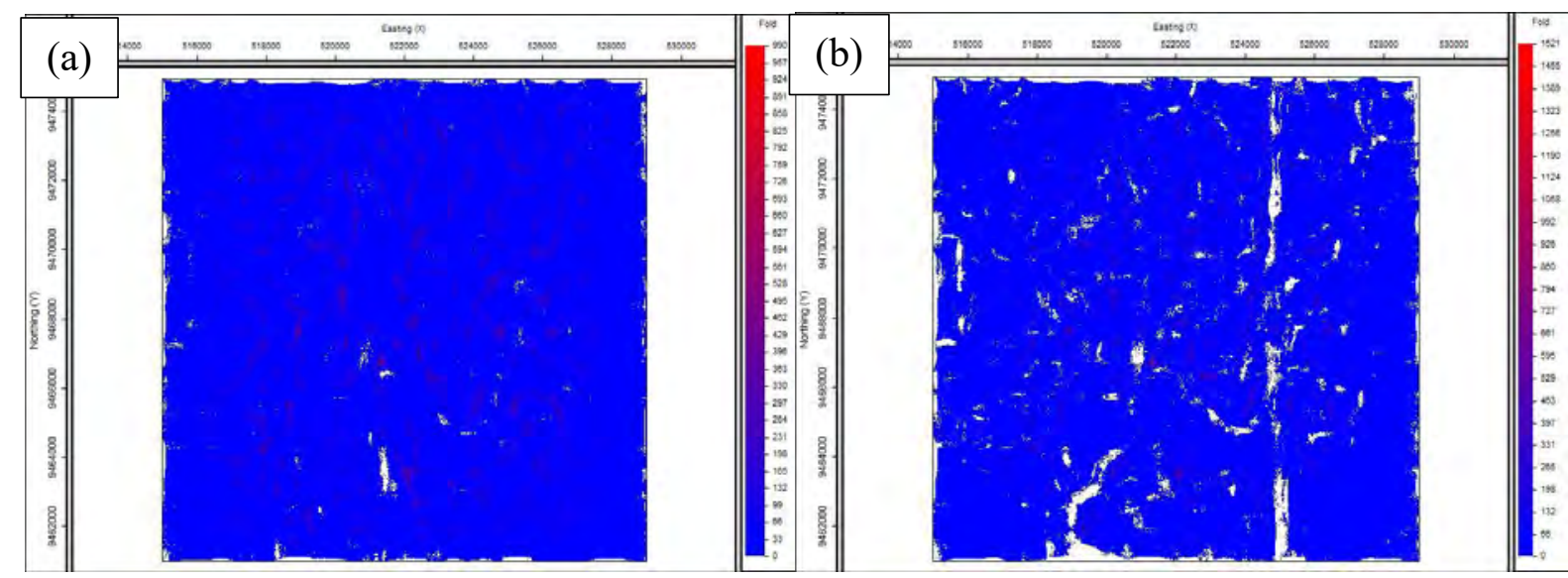

Gambar 9. Distribusi Fold Migrated (illumination) Konfigurasi Bentangan Brick Template Narrow Azimuth, (a). Formasi 3 dan (b). Formasi 4 